\title{
Analysis of the relationships between edentulism, periodontal health, body composition, and bone mineral density in elderly women
}

This article was published in the following Dove Press journal:

Clinical Interventions in Aging

23 March 2016

Number of times this article has been viewed

\author{
Zofia Ignasiak' \\ Malgorzata Radwan-Oczko² \\ Krystyna Rozek-Piechura ${ }^{3}$ \\ Marta Cholewa ${ }^{4}$ \\ Anna Skrzek ${ }^{5}$ \\ Tomasz Ignasiak $^{6}$ \\ Teresa Slawinska' \\ 'Department of Biostructure, \\ University School of Physical \\ Education, Wroclaw, Poland; \\ ${ }^{2}$ Department of Periodontology, \\ Wroclaw Medical University, Wroclaw, \\ Poland; ${ }^{3}$ Department of Physiotherapy \\ and Occupation Therapy in Internal \\ Diseases, University School of \\ Physical Education, Wroclaw, Poland; \\ ${ }^{4}$ DENTARAMA Dentistry Center, \\ Walbrzych, Poland; ${ }^{5}$ Department \\ of Physiotherapy and Ocupation \\ Therapy in Motor-System \\ Dysfunction, University School of \\ Physical Education, Wroclaw, Poland; \\ ${ }^{6}$ Karkonosze State Higher School in \\ Jelenia Gora, Jelenia Gora, Poland
}

Correspondence: K Rozek-Piechura University School of Physical Education, Paderewski 35, 5I-6I2 Wroclaw, Poland Email krystyna.rozek-piechura@awf. wroc.pl
Objective: The relationship between bone mineral density (BMD) and tooth loss in conjunction with periodontal disease is not clear. The suggested effects include alteration in bone remodeling rates as well as the multifaceted etiology of edentulism. There is also a question if other body-related variables besides BMD, such as body composition, may be associated with tooth number and general periodontal health. The aim of this study was to evaluate if tooth number and marginal periodontal status are associated with body composition and BMD in a sample of elderly women.

Materials and methods: The study involved 91 postmenopausal women. Data included basic anthropometric characteristics, body composition via bioelectrical impedance analysis, and BMD analysis at the distal end of the radial bone of the nondominant arm via peripheral dual-energy X-ray absorptiometry. A dental examination was performed to assess tooth number, periodontal pocket depth (PD), and gingival bleeding.

Results: In nonosteoporotic women, a significant positive correlation was found between BMD and lean body mass, total body water, and muscle mass. The indicators of bone metabolism correlated negatively with PD. Such relationships did not appear in osteoporotic women. In both groups, basic anthropometric characteristics and body composition were significantly and positively correlated with PD and bleeding on probing.

Conclusion: The results suggest that body composition and BMD are not significantly correlated with tooth number and gingival bleeding.

Keywords: tooth number, bone mineral density, fat mass, lean body mass

\section{Introduction}

Health-related quality of life has become the de jure guiding principle in health care policy and among medical providers. This tenant is focused on improving health and quality of life at all life stages. As life expectancy has steadily increased over time, the biological processes of aging are ever more intensified to present a wide array of systemic diseases that affect today's seniors (aged 60+ years). However, in this population, the sense of healthy well-being is highly variable and subjective. Gerontological research is increasing in pace and is focused on not only identifying aging-associated diseases as well as developing relevant treatments and preventive measures but also expanding in scope to understand the effects of socioeconomic status among the elderly. ${ }^{1-9}$ There are also an increasing number of studies focused on the mutual relationships between the physiological process associated with a healthy lifestyle and maintaining quality of life during senescence. ${ }^{2,9}$ The literature points to 
many complex relationships among a variety of internal and external factors, among which the most frequently cited are nutrition, lifestyle, and physical activity.

The increasing significance of aging-associated diseases has made osteoporosis, next to obesity, designated as part of the " 21 st century epidemic" by the World Health Organization (WHO), and it has become a focal point among today's health issues. ${ }^{10-12}$ Osteoporosis is understood as incredibly complex and multivariate, dependent on age, sex (as it more often affects women), race, gonadal hormone levels (especially, estrogen deficiency), early menopause, low calcium intake, ${ }^{13}$ nutrition, and physical activity level. ${ }^{12,14-17}$ Osteoporosis behaves as a global metabolic systemic disease of the skeleton and is manifested by a progressive decrease in bone mineral density (BMD). In this way, it is a risk factor for many diseases including edentulism and periodontitis. Chronic periodontal disease is an inflammatory condition associated with the loss of connective and bone tissue along the alveolar ridges. Owing to its incidence, it is considered a lifestyle disease. Among the associated risk factors, the literature has identified gingivitis caused by the presence of dental plaque, the increased presence of plaque-retentive areas, an improper or imbalanced diet, smoking, decreased immunity, middle age, low socioeconomic status, and genetic predispositions. ${ }^{18,19}$

In addition, abnormal metabolic processes within the mandible and maxilla can promote edentulism and vice versa, where tooth loss regardless of cause can lead to the development of atrophic processes in both alveolar arches. ${ }^{20}$ Of interest is the fact that the literature has also identified several common risk factors between osteoporosis and chronic periodontitis, including advanced age, smoking, and calcium and/or vitamin $\mathrm{D}$ deficit, and that both pathologies are free of warning signs and symptoms during onset. ${ }^{21}$ However, there is a lack of consensus among researchers as to the relationship between osteoporosis, tooth loss, and the incidence of periodontal disease. While some researchers have determined no direct correlation between low BMD (osteoporosis) and dental count, ${ }^{16,22}$ other authors have shown that the number of teeth does correlate with BMD. ${ }^{14,23}$ It can be assumed that this discrepancy is related to alteration in bone remodeling rates and that the etiology of tooth loss is influenced by numerous factors, including a lack of proper oral hygiene or various early age dental and periodontal pathologies.

Another confounding issue is the comparability of research methods. The lack of uniform test methods for assessing maxillary and mandibular osteoporosis impedes reliable comparison from being made of available data sets. Further complications arise from the fact that bone metabolism differs throughout the skeleton, where the mandible is largely composed of compact bone while the maxilla the cancellous bone. At the same time, the reasons above give rise to the question whether other variables (besides BMD), such as anthropometric indicators, may be associated with tooth number and periodontal status. Therefore, the aim of the present study is to evaluate if tooth number and marginal periodontal status (periodontal pocket depth [PD] and gingival bleeding) are associated with body composition and BMD in an elderly female population.

\section{Materials and methods}

The study sampled 91 postmenopausal women between 60 and 82 years of age (mean 64.72 years). All declared they were healthy (exclusion criteria included prior myocardial infarction or stroke, hypertension, active cancer, and any medical contraindication precluding involvement in the study) and provided their written informed consent for voluntary participation. The study protocol was approved by the Senate Ethics Committee for Scientific Research of the University School of Physical Education in Wrocław, Wrocław, Poland, and conducted as part of NCN project NN404075337. All measurements were performed at the same institution by faculty members of the Department of Biostructure Research.

Body height and mass were recorded using a measuring station (model 764; Seca, Hamburg, Germany) and body mass index (BMI) was calculated (WHO BMI classification criteria were adopted). Body composition was assessed by bioelectrical impedance analysis using a multifrequency segmental body composition analyzer (MC-180MA; Tanita, Tokyo, Japan) to estimate body fat mass, body fat percentage, lean body mass (LBM), total body water (TBW), and muscle mass.

BMD was measured at the distal end of the radial bone of the nondominant arm by peripheral dual-energy X-ray absorptiometry with the use of a peripheral densitometry device (EXA-3000; OsteoSys, Seoul, South Korea). The measures selected for analysis included absolute BMD; T-score, as a percentage and standard deviation compared with the normal reference mean of the 30-35-year-old population; and $Z$-score, as a percentage and standard deviation compared with the age-matched normal BMD.

WHO criteria were adopted to measure the level of osteoporosis and predict future fracture, where a $\mathrm{T}$-score of $>-1$ is defined as normal, a T-score between -1.0 and -2.5 is defined as osteopenia moderate risk, and a T-score $<-2.5$ is defined as osteoporosis. 
A dental examination was performed by a dentist to determine tooth number, periodontal PD, and gingival bleeding index via bleeding on probing. ${ }^{24}$

Basic descriptive statistics (mean, standard deviation, total, and minimum and maximum) were calculated for all measures. Student's $t$-test for independent samples was used to determine statistically significant differences with an adopted significance level of $P \leq 0.05$. Rank correlation coefficients were calculated to evaluate the relationships between the variables, with correlations at $P \leq 0.05$ regarded as significant.

\section{Results}

To aid analysis, we divided the participants into two groups. The first group (I) encompassed 44 women $(48.4 \%$ of the sample) with normal BMD or osteopenia. The second group (II) included 47 women ( $51.6 \%$ of the sample) with diagnosable osteoporosis or severe osteoporosis. The collected data are presented according to these groups (Table 1). When comparing the two groups, it was found that the women in group I were significantly younger than those in group II. Furthermore, the basic anthropometric characteristics (height, mass, and BMI) were significantly larger in women without osteoporosis. Of interest was that fact that BMI in group I bordered class I obesity, whereas the osteoporotic women presented a mean BMI slightly above normal (classified as mildly overweight). The body composition and BMD measures (absolute BMD, young reference mean, and agematched values) were significantly lower in group II.

No differences were found in tooth number between groups I and II (19.77 and 18.9, respectively). The marginal periodontium status (PD and gingival bleeding) was also nearly identical in both groups. The mean gingival bleeding was $39.9 \%$ and $39.1 \%$ in groups I and II, respectively, and indicated inflammation. The mean periodontal PD did not differ between the normal/osteopenic group and the osteoporosis group (2.86 and $2.89 \mathrm{~mm}$, respectively). It should be mentioned that these values were close to normal and did not confirm the presence of advanced periodontal disease.

Significant correlations were found in group I between body mass and BMI with all of the body composition and BMD variables (Table 2). In addition, significant positive correlations were observed between LBM, TBW, and muscle mass by comparing all the BMD scores; the higher the body composition values, the higher the BMD score values.

The number of teeth and the presence of inflammation via gingival bleeding did not show any significant correlation with the body composition measures and BMD. Only mean periodontal PD correlated (negatively) with the BMD measures (absolute BMD, T-score, Z-score). This indicated that shallower periodontal pockets are associated with higher absolute BMD, young reference mean, and age-matched values but only in the normal/osteopenic group.

Table I Descriptive statistics of the selected anthropometric and dental characteristics

\begin{tabular}{|c|c|c|c|c|c|c|c|c|c|c|c|c|}
\hline \multirow[t]{2}{*}{ Variable } & \multicolumn{5}{|c|}{ Normal BMD and osteopenia $(n=44)$} & \multicolumn{5}{|c|}{$\begin{array}{l}\text { Osteoporosis and severe osteoporosis } \\
(n=47)\end{array}$} & \multicolumn{2}{|c|}{ Student's t-test } \\
\hline & $\bar{x}$ & SD & $\mathbf{v}$ & Min & Max & $\overline{\boldsymbol{x}}$ & SD & $\mathbf{v}$ & Min & Max & $\boldsymbol{t}$ & $P$-value \\
\hline Age (years) & 62.92 & 5.16 & 8.20 & 60.91 & 78.25 & 66.52 & 5.28 & 7.93 & 60.67 & 82.19 & -3.29 & 0.0014 \\
\hline Body height $(\mathrm{cm})$ & 160.56 & 5.95 & 3.71 & 145.90 & 172.40 & 157.67 & 4.60 & 2.92 & 146.50 & 168.00 & 2.59 & 0.0111 \\
\hline Body mass (kg) & 76.32 & 12.26 & 16.06 & 57.60 & 108.20 & 64.96 & 10.38 & 15.99 & 48.10 & 85.60 & 4.78 & 0.0000 \\
\hline BMI & 29.64 & 4.73 & 15.96 & 21.70 & 44.18 & 26.12 & 3.96 & 15.16 & 19.19 & 34.54 & 3.86 & 0.0002 \\
\hline Fat (\%) & 35.45 & 5.11 & 14.42 & 17.40 & 46.50 & 32.89 & 6.32 & 19.22 & 18.80 & 43.00 & 2.12 & 0.0371 \\
\hline Fat (kg) & 27.36 & 7.57 & 27.67 & 12.45 & 46.95 & 21.86 & 7.16 & 32.77 & 9.35 & 36.60 & 3.56 & 0.0006 \\
\hline LBM (kg) & 48.69 & 5.84 & 11.99 & 39.60 & 61.60 & 42.99 & 4.10 & 9.53 & 36.60 & 51.45 & 5.42 & 0.0000 \\
\hline Body water (L) & 34.41 & 4.15 & 12.07 & 27.90 & 43.70 & 30.28 & 2.94 & 9.70 & 25.75 & 36.50 & 5.50 & 0.0000 \\
\hline Muscle mass (kg) & 46.22 & 5.55 & $12.0 \mid$ & 37.60 & 58.50 & 40.80 & 3.89 & 9.55 & 34.75 & 48.85 & 5.42 & 0.0000 \\
\hline BMD & 0.41 & 0.06 & 14.92 & 0.34 & 0.63 & 0.27 & 0.05 & 18.78 & 0.15 & 0.36 & 11.66 & 0.0000 \\
\hline T-score (\%) & 83.16 & 11.01 & 13.24 & 69.77 & 114.22 & 55.73 & 10.15 & 18.21 & 38.19 & 74.35 & 12.37 & 0.0000 \\
\hline T-score & -1.37 & 0.90 & -68.72 & -2.46 & 1.16 & $-3.6 I$ & 0.82 & -22.8 & -5.00 & -2.09 & 12.35 & 0.0000 \\
\hline Z-score (\%) & 105.70 & 14.86 & 14.06 & 74.06 & 146.88 & 71.98 & 13.58 & 18.87 & 40.14 & 96.34 & $\mid 1.31$ & 0.0000 \\
\hline Z-score & 0.35 & 0.89 & 231.52 & -1.48 & 2.75 & $-1.6 \mid$ & 0.77 & -47.67 & -3.53 & -0.21 & 11.22 & 0.0000 \\
\hline Tooth number (n) & 19.77 & 5.79 & 29.31 & 5.00 & 27.00 & 18.19 & 7.15 & 39.32 & 3.00 & 28.00 & 1.15 & 0.2516 \\
\hline GBI & 39.93 & 12.46 & 31.19 & 21.00 & 78.00 & 39.11 & 10.92 & 27.92 & 13.00 & 68.00 & 0.34 & $0.737 \mid$ \\
\hline PD & 2.86 & 0.49 & 17.04 & 2.20 & 4.34 & 2.89 & 0.36 & 12.56 & 2.00 & 3.63 & -0.33 & 0.7449 \\
\hline
\end{tabular}

Notes: Data in bold indicates statistical significance at $P<0.05$.

Abbreviations: BMD, bone mineral density; SD, standard deviation; Min, minimum; Max, maximum; BMI, body mass index; LBM, lean body mass; GBI, gingival bleeding index; PD, pocket depth; $\bar{x}$, mean value; $t$, value of Student's $t$-test; $v$, coefficient of variation. 
Table 2 Spearman's correlation coefficients for the effects of the anthropometric and dental characteristics

\begin{tabular}{|c|c|c|c|c|c|c|c|c|c|c|c|c|c|c|c|}
\hline Variable & Age & $\begin{array}{l}\text { Body } \\
\text { height }\end{array}$ & $\begin{array}{l}\text { Body } \\
\text { mass }\end{array}$ & BMI & Fat (\%) & Fat (kg) & LBM & $\begin{array}{l}\text { Body } \\
\text { water }\end{array}$ & $\begin{array}{l}\text { Muscle } \\
\text { mass }\end{array}$ & BMD & T-score & Z-score & $\begin{array}{l}\text { Tooth } \\
\text { number }\end{array}$ & GBI & PD \\
\hline Age & - & -0.03 & 0.02 & 0.06 & 0.16 & 0.11 & -0.07 & -0.09 & -0.07 & -0.07 & -0.08 & 0.02 & -0.20 & 0.11 & 0.00 \\
\hline Body height & -0.07 & - & 0.27 & -0.04 & 0.16 & 0.27 & 0.39 & 0.39 & 0.39 & -0.14 & -0.13 & -0.14 & -0.23 & 0.03 & 0.06 \\
\hline Body mass & 0.17 & 0.24 & - & 0.94 & 0.83 & 0.93 & 0.82 & 0.81 & 0.82 & 0.11 & 0.10 & 0.10 & 0.00 & 0.02 & 0.10 \\
\hline BMI & 0.21 & -0.18 & 0.89 & - & 0.79 & 0.87 & 0.72 & 0.71 & 0.72 & 0.14 & 0.13 & 0.13 & 0.07 & 0.00 & 0.11 \\
\hline Fat (\%) & 0.21 & -0.07 & 0.72 & 0.74 & - & 0.96 & 0.44 & 0.44 & 0.44 & -0.07 & -0.08 & -0.08 & -0.05 & 0.01 & 0.10 \\
\hline Fat $(\mathrm{kg})$ & 0.18 & 0.12 & 0.93 & 0.87 & 0.91 & - & 0.65 & 0.65 & 0.65 & -0.01 & -0.02 & -0.02 & -0.04 & 0.02 & 0.09 \\
\hline LBM & 0.09 & 0.38 & 0.85 & 0.68 & 0.36 & 0.65 & - & 1.00 & 1.00 & 0.23 & 0.23 & 0.23 & -0.01 & 0.05 & 0.06 \\
\hline Body water & 0.06 & 0.39 & 0.85 & 0.67 & 0.36 & 0.65 & 1.00 & - & 1.00 & 0.23 & 0.23 & 0.22 & 0.00 & 0.04 & 0.07 \\
\hline Muscle mass & 0.09 & 0.38 & 0.85 & 0.68 & 0.36 & 0.65 & 1.00 & 1.00 & - & 0.23 & 0.23 & 0.23 & -0.01 & 0.05 & 0.06 \\
\hline BMD & 0.01 & -0.06 & 0.32 & 0.36 & 0.04 & 0.18 & 0.48 & 0.46 & 0.48 & - & 1.00 & 0.99 & 0.00 & 0.08 & 0.00 \\
\hline T-score & 0.00 & -0.05 & 0.32 & 0.36 & 0.04 & 0.19 & 0.48 & 0.46 & 0.48 & 1.00 & - & 0.99 & -0.01 & 0.09 & 0.01 \\
\hline Z-score & 0.17 & -0.13 & 0.35 & 0.42 & 0.11 & 0.24 & 0.47 & 0.45 & 0.47 & 0.97 & 0.97 & - & -0.03 & 0.07 & -0.01 \\
\hline Tooth number & 0.27 & -0.24 & -0.20 & -0.09 & -0.18 & -0.19 & -0.15 & -0.14 & -0.15 & 0.01 & 0.01 & -0.02 & - & -0.43 & -0.47 \\
\hline GBI & -0.09 & -0.21 & 0.10 & 0.17 & 0.22 & 0.15 & -0.04 & -0.04 & -0.04 & -0.23 & -0.23 & -0.20 & -0.01 & - & 0.38 \\
\hline PD & 0.00 & 0.07 & 0.20 & 0.16 & 0.23 & 0.21 & 0.09 & 0.08 & 0.09 & -0.35 & -0.35 & -0.30 & -0.28 & 0.38 & - \\
\hline
\end{tabular}

Notes: Left triangle, normal BMD and osteopenia participants; right triangle, osteoporosis and severe osteoporosis. Values in bold are statistically significant at $P<0.05$. Abbreviations: BMD, bone mineral density; BMI, body mass index; LBM, lean body mass; GBI, gingival bleeding index; PD, pocket depth.

In clinical terms, the etiology and pathogenesis of periodontal disease are confirmed by our results, in that examination of the marginal periodontium showed that tooth number was negatively correlated with bleeding on probing and periodontal PD. As a result, lower tooth count was indicative of diminished marginal periodontium health (via increased inflammation and deeper periodontal pockets). Moreover, the positive correlation between periodontal $\mathrm{PD}$ and the presence of inflammation (via gingival bleeding) indicates that the higher bleeding index is associated with increased PD. This trend was observed in both groups of participants.

In women with osteoporosis, the correlations between the analyzed measures were reversed from what was observed in the normal BMD/osteopenia group. Only the basic anthropometric characteristics showed significant (positive) correlations with body composition or periodontal PD and gingival bleeding. In contrast to group I, the BMD variables did not show any correlations with the body composition and dental measures. However, a negative correlation was identified between the number of teeth with gingival bleeding and periodontal PD.

\section{Discussion}

The literature shows a large body of research on obesity, periodontal and tooth pathologies, metabolic bone diseases, and edentulism. Chaffee and Weston ${ }^{25}$ conducted an extensive meta-analysis of the relationships between periodontal disease and obesity. They concluded that obesity is a serious risk factor for periodontal disease and tooth loss among adults throughout the world. This study's examination of the issue did not confirm a significant relationship between BMI and fat tissue with the selected dental variables as well as tooth number. The cause of this may stem from the fact that the majority of participants were overweight albeit not obese, where their body fat percentage was bordering acceptable levels.

When considering the relationship between bone remodeling, periodontal health, and tooth number, the literature also shows no congruence. ${ }^{14,16,26}$ Some researchers claim that a relationship exists between osteoporosis and tooth number with periodontal status, while others argue the reverse in that impaired bone metabolism is not directly related to tooth loss while also recognizing that osteoporosis is a risk factor for dental and periodontal disease.

A meta-analysis of 35 studies on the relationship between osteoporosis and periodontitis by Martinez-Maestre et $\mathrm{a}^{21}$ was also unable to identify any clear trends. A majority of the findings involving radiological examination of maxilla and mandible bone health did indicate a positive correlation with osteoporosis. However, other studies found no relationship or were inconclusive, although this may be the result of alternative methodologies, including the examination of different anatomic sites or the adoption of dissimilar criteria of periodontal health status. Moreover, the authors highlighted the fact that findings based on a periodontal examination in a clinical setting are contentious. To further complicate the matter, Pejčić et $\mathrm{al}^{27}$ found no differences in periodontal health between patients with and without osteoporosis after a clinical assessment, although it needs to mention that their study was performed on small groups of 25 individuals. In turn, Aspalli et $\mathrm{a}^{28}$ found a significant negative correlation only 
between T-score and periodontal PD and clinical attachment loss, while other clinical indicators of periodontal disease were not significantly correlated with bone status. Additional studies have confirmed significantly worse periodontal status identified via gingival inflammation, bleeding, and clinical attachment loss in osteoporotic patients compared with healthy female controls. ${ }^{29} \mathrm{Al}$ Habashneh et al, ${ }^{30}$ in turn, did not confirm any differences in the degree of clinical attachment loss, although multivariate analysis indicated a higher probability of clinical attachment loss and periodontitis in osteoporotic women. In their study, osteoporosis was significantly correlated with alveolar crestal bone loss. In light of the above, it is apparent that the present findings are ambiguous and that additional research is needed.

The obtained results may indicate that edentulism may be due to damage to tooth-supporting structures by chronic periodontitis and not as an effect of any global factor responsible for decreased bone density.

\section{Conclusion}

1) The present study suggests that body composition and BMD are not significantly correlated with tooth number and gingival bleeding. 2) In nonosteoporotic women, BMD showed a significant positive correlation with LBM, TBW, and muscle mass, while BMD was negatively correlated with periodontal PD. Such relationships did not appear in the osteoporotic women. 3) In both osteoporotic and nonosteoporotic women, basic anthropometric characteristics and body composition were significantly positively correlated with PD and gingival bleeding.

\section{Disclosure}

The authors report no conflicts of interest in this work.

\section{References}

1. Assmann G, Cullen P, Jossa F, Lewis B, Mancini M. Coronary heart disease: reducing the risk: the scientific background to primary and secondary prevention of coronary heart disease. A worldwide view. International task force for the prevention of coronary heart disease. Arterioscler Thromb Vasc Biol. 1999;19:1819-1824.

2. Barrett RS, Lichtwark GA. Effect of altering neural, muscular and tendinous factors associated with aging on balance recovery using the ankle strategy: a simulation study. J Theor Biol. 2008;254:546-554.

3. Buchman AS, Boyle PA, Wilson RS, Gu L, Bienias JL, Bennett DA. Pulmonary function, muscle strength and mortality in old age. Mech Ageing Dev. 2008;129:625-631.

4. Jousilahti P, Vartiainen E, Tuomilehto J, Puska P. Sex, age, cardiovascular risk factors, and coronary heart disease: a prospective follow-up study of 14786 middle-aged men and women in Finland. Circulation. 1999;99:1165-1172.

5. Madureira MM, Takayama L, Gallinaro AL, Caparbo VF, Costa RA, Pereira RM. Balance training program is highly effective in improving functional status and reducing the risk of falls in elderly women with osteoporosis: a randomized controlled trial. Osteoporos Int. 2007;18: 419-425.
6. Cruz-Jentoft AJ, Baeyens JP, Bauer JM, et al. Sarcopenia: European consensus on definition and diagnosis: report of the European Working Group on Sarcopenia in older people. Age Ageing. 2010;39:412-423.

7. Mosakowska M, Więcek A, Błędowski P, editors. [POLSENIOR. Medical, Psychological, Sociological and Economic Aspects of Aging in Poland]. Poznań: Termedia Wydawnictwa Medyczne; 2012.

8. Ritchie CS. Obesity and periodontal disease. Periodontol 2000. 2007; 44:154-163.

9. Peel NM, McClure RJ, Bartlett HP. Behavioral determinants of healthy aging. Am J Prev Med. 2005;28:298-304.

10. Reid IR. Relationships between fat and bone. Osteoporos Int. 2008;19: 595-606.

11. Skrzek A, Ignasiak Z, Koziel S. Different involutionary changes in bone mineral density with age in three skeletal sites in healthy polish women. Homo. 2011;62:359-367.

12. Wiacek M, Skrzek A, Ignasiak Z, Zubrzycki IZ. The changes of bone mineral density in relation to body mass index and aging among polish and different ethnic women in the United States: cross-sectional studies. J Clin Densitom. 2010;13:307-314.

13. Kaye EK. Bone health and oral health. J Am Dent Assoc. 2007;138: 616-619.

14. von Wowern N. General and oral aspects of osteoporosis: a review. Clin Oral Investig. 2001;5:71-82.

15. Chesnut $\mathrm{CH}$ 3rd. The relationship between skeletal and oral bone mineral density: an overview. Ann Periodontol. 2001;6:193-196.

16. Bałczewska E. Stan uzębienia u kobiet z chorobami przyzębia i obniżoną gęstością mineralną kośćca. [Dental health in women with periodontal disease and decreased mineral bone density]. Czas Stomat. 2005;58:789-808.

17. Zdziemborska A, Deszczyńska K, Fidecki M. Osteoporoza - Bisfosfoniany - Dentysta. Część I. [Osteoporosis - bisphosphonate-dentist. Part I]. Nowa Stomat. 2012;1:15-18.

18. Savage A, Eaton KA, Moles DR, Needleman I. A systematic review of definitions of periodontitis and methods that have been used to identify this disease. J Clin Periodontol. 2009;36:458-467.

19. Siukosaari P, Ajwani S, Ainamo A, Wolf J, Narhi T. Periodontal health status in the elderly with different levels of education: a 5-year follow-up study. Gerodontology. 2012;29(2):170-178.

20. Kloss FR, Gassner R. Bone and aging: effects on the maxillofacial skeleton. Exp Gerontol. 2006;41:123-129.

21. Martinez-Maestre MA, Gonzalez-Cejudo C, Machuca G, Torrejon R, Castelo-Branco C. Periodontitis and osteoporosis: a systematic review. Climacteric. 2010;13:523-529.

22. Elders PJ, Habets LL, Netelenbos JC, van der Linden LW, van der Stelt PF. The relation between periodontitis and systemic bone mass in women between 46 and 55 years of age. J Clin Periodontol. 1992;19:492-496.

23. Wactawski-Wende J. Periodontal diseases and osteoporosis: association and mechanisms. Ann Periodontol. 2001;6:197-208.

24. Ainamo J, Bay I. Problems and proposals for recording gingivitis and plaque. Int Dent J. 1975;25:229-235.

25. Chaffee BW, Weston SJ. Association between chronic periodontal disease and obesity: a systematic review and meta-analysis. J Periodontol. 2010;81:1708-1724.

26. Guiglia R, Di FO, Lo RL, Sprini D, Rini GB, Campisi G. Osteoporosis, jawbones and periodontal disease. Med Oral Patol Oral Cir Bucal. 2013; 18:e93-e99.

27. Pejčić A, Kojović D, Grigorov I, Stamenković B. Periodontitis and osteoporosis. Facta Univ. 2005;12:100-103.

28. Aspalli SS, Shetty VS, Parab PG, Nagappa G, Devnoorkar A, Devarathnamma MV. Osteoporosis and periodontitis: is there a possible link? Indian J Dent Res. 2014;25:316-320.

29. Pepelassi E, Nicopoulou-Karayianni K, Archontopoulou AD, et al. The relationship between osteoporosis and periodontitis in women aged 45-70 years. Oral Dis. 2012;18:353-359.

30. Al Habashneh R, Alchalabi H, Khader YS, Hazza'a AM, Odat Z, Johnson GK. Association between periodontal disease and osteoporosis in postmenopausal women in Jordan. J Periodontol. 2010;81:1613-1621. 


\section{Publish your work in this journal}

Clinical Interventions in Aging is an international, peer-reviewed journal focusing on evidence-based reports on the value or lack thereof of treatments intended to prevent or delay the onset of maladaptive correlates of aging in human beings. This journal is indexed on PubMed Central, MedLine,

CAS, Scopus and the Elsevier Bibliographic databases. The manuscript management system is completely online and includes a very quick and fair peer-review system, which is all easy to use. Visit http://www.dovepress. com/testimonials.php to read real quotes from published authors. 